specificity and its nuclear transport will guide future strategic directions for the Alzheimer-disease research community.

\section{REFERENCES}

Belyaev ND et al (2009) EMBO Rep 10: 94-100 Belyaev ND et al (2010) J Biol Chem 285:

41443-41454

Clark RD et al (2009) Genet Med 11: 769-775 Goate A et al (1991) Nature 349: 704-706

Goodger ZV et al (2009) / Cell Biol 122: 3703-3714

Huysseune S et al (2009) FASEB / 23: 4158-4167

Pardossi-Piquard R et al (2005) Neuron 46: 541-554
Wang X et al (2006) Proc Natl Acad Sci USA 103: 17284-17289

Xu X et al (2011) EMBO Rep 12: 216-222

Anthony J. Turner, Nikolai D. Belyaev \& Natalia N. Nalivaeva are at the Institute of Molecular \& Cellular Biology, Faculty of Biological Sciences, University of Leeds, Leeds, UK.

E-mail:a.j.turner@leeds.ac.uk

EMBO reports (2011) 12, 180-181.

doi:10.1038/embor.2011.25

\title{
Microbial rights?
}

\section{Charles S. Cockell}

S ynthetic biology and the increasing complexity of molecular biology have brought us to the stage at which we can synthesize new microorganisms. This has generated pressing questions about whether these new organisms have any place in our system of ethics and how we should treat them.

The idea that microbes might have some moral claims on us beyond their practical uses or instrumental value is not a new question. Microbiologist Bernard Dixon (1976) presciently asked whether it was ethical to take the smallpox virus to extinction at the height of the attempts of the World Health Organization in the 1970s to eradicate it. There is no unambiguous answer. Today, we might still ask this question, but we might extend it to ask whether the destruction or extinction of a synthetic microbe that was made by humans is also ethically questionable or is such an entityin that it is designed-more like a machine, which we have no compunction in terminating? Would two lethal pathogens, one of them synthetic and one of them natural, but otherwise identical, command the same moral claims?

In a colloquial way, we might ask whether microbes have rights. In previous papers (Cockell, 2004) I have discussed the 'rights' of microbes and further explored some issues about the ethics we apply to them (Cockell, 2008). Julian Davies, in a recent opinion article in $\mathrm{EMBO}$ reports (Davies, 2010) described my assertion that they should have constitutional rights as 'ridiculous'. Although I did suggest that environmental law could be changed to recognize the protection of microbial ecosystems-which would imply statutory rights or protection-nowhere have I claimed that microbes should have 'constitutional' rights. Nevertheless, this misattribution provides a useful demonstration of the confusion that exists about exactly how we should treat microbes.

Few people are in any doubt that microbes should be conserved for their direct uses to humans, for example, in food and drug production, and their indirect uses such as the crucial role they have in the health of ecosystems. Indeed, these motivations can be used to prioritize microbial conservation and protection efforts (Cockell \& Jones, 2009). The crucial question is whether microbes have 'intrinsic value' beyond their practical uses. If the answer is 'no', then we should have no guilt about deliberately driving microbes to extinction for our benefit. However, there are people who feel uneasy with this conclusion, a feeling that calls forth more complex ethical questions.

The question is whether microbes have some sort of 'interests' that make demands on our treatment of them that go beyond a mere utilitarian calculation. These arguments themselves question what we define as 'interests' and whether interests make demands on us. A microbe has no future plans or thought processes; the sorts of interests that are accepted as being of sufficient scope to place demands on our treatment of other human beings, for instance. However, microbes do have biological interests. A halophilic microbe might eventually die if it is dropped into freshwater. Does our knowledge of what is in the biological interests of a microbe mean that we must show it any consideration beyond practical uses? The answer is not obviously negative (Taylor, 1981), but even if we decide that it is, this does not let us off the hook quite yet.

There are other intrinsic value arguments that are more obscure, particularly those around the notion of 'respect'; the idea that we should show empathy towards the trajectory, however deterministic, of other life forms. These unquantifiable and controversial arguments might, nevertheless, partly explain any unease that we have in watching a group of people smash up and destroy some exquisite microbial mats, just because they were bored.

Clearly, human instrumental needs do trump microbes at some level. If they did not, we could not use bleach in our houses, an absurd end-point raised in a 1970s science fiction story that explored the futuristic ramifications of full microbial rights, in which household bleaches and deodorants are banned (Patrouch, 1977).

However, we should not be so quick to ridicule ideas about microbial ethics and rights. Although it might be true that phages kill a large percentage of the bacterial population of the world every few days, as Julian Davies points out, human society has achieved an unprecedented capacity for destruction and creation. Our ability to poison and disrupt habitats has been unquantified, with respect to the loss of microbial species. Both synthetic biology and bioterrorism raise the spectre of creating new organisms, including pathogens, which we might need to control or deliberately pursue to extinction. Dixon's dilemma about the smallpox virus, raised more than 30 years ago, has become an urgent point of discussion in the ethics of molecular biology and microbiology.

\section{REFERENCES}

Cockell CS (2004) Interdiscip Sci Rev 29: 141-150

Cockell CS (2008) Ethics Environ 13: 23-39

Cockell CS, Jones HL (2009) Oryx 43: 520-526

Davies J (2010) EMBO Rep 11: 721

Dixon B (1976) New Scientist 26: 430-432

Patrouch J (1977) Analog Science Fiction and Fact 97: 167-169

Taylor P (1981) Environmental Ethics 3: 197-218

\section{Charles S. Cockell is at the Open University in the UK. \\ E-mail:c.s.cockell@open.ac.uk}

EMBO reports (2011) 12, 181. doi:10.1038/embor.2011.13 